\title{
ANALISIS PENERAPAN LAJUR KHUSUS SEPEDA MOTOR TERHADAP KINERJA RUAS JALAN
}

\author{
Intan Permata Sari ${ }^{(1)}$, Eva Azhra Latifa ${ }^{(2)}$ \\ ${ }^{1}$ Jurusan Teknik Sipil Program Studi Perancangan Jalan dan Jembatan Politeknik Negeri Jakarta, \\ Kampus Baru UI Depok 16424.e-mail: intanpermatasari811@gmail.com \\ ${ }^{2}$ Dosen Jurusan Teknik Sipil, Politeknik Negeri Jakarta, Kampus Baru UI Depok 16424. e-mail: \\ evaazhra@gmail.com
}

\begin{abstract}
ABSTRAK
Jumlah sepeda motor yang ada di jalan mempengaruhi tingkat pelayanan serta karakteristik lalu lintas ruas jalan. Masalah perilaku pengendara sepeda motor yang cenderung tidak tertib membuat tingkat pelayanan jalan sangat terpengaruh. Salah satu solusi yang dapat digunakan adalah dengan menyediakan lajur khusus sepeda motor. Studi ini diawali dengan pengumpulan data sesuai dengan parameter yang diperlukan sebagai dasar penentuan perlunya lajur khusus sepeda motor dan analisis antara lain analisis kinerja jalan yaitu kapasitas, derajat kejenuhan, tingkat pelayanan, serta kecepatan. Kriteria penting untuk kebutuhan lajur sepeda motor adalah proporsi sepeda motor besar dari 34,5\% dalam smp/jam. Berdasarkan hasil analisis volume motor memiliki pengaruh besar terhadap derajat kejenuhan serta tingkat pelayanan. Secara keseluruhan,dampak penerapan lajur khusus sepeda motor sangat efektif untuk menaikkan kinerja jalan karena tingkat pelayanan naik dari F menjadi C. Sementara untuk lajur non sepeda motor mengalami sedikit penurunan tingkat pelayanan dari B menjadi C. Proyeksi kejenuhan jalan dengan melihat pertumbuhan kendaraan 5 tahun ke depan, didapatkan hasil yang tidak relevan antara kejenuhan yang sangat tinggi pada lajur khusus motor sebesar 1,44 dengan kecepatan lajur hasil simulasi vissim yang masih normal yaitu $38 \mathrm{~km} / \mathrm{jam}$. Dilakukan solusi dengan merubah nilai EMP motor dari 0,25 menjadi 0,13 . Hasil analisis menunjukkan penurunan yang signifikan pada kejenuhan sepeda motor yaitu sebesar 0,75 sehingga hasil kejenuhan menjadi relevan dengan kecepatan lajur khusus hasil simulasi.
\end{abstract}

Kata kunci: analisis kinerja jalan, lajur khusus sepeda motor, sepeda motor, tingkat pelayanan.

\begin{abstract}
The number of motorcycles on the road affects level of the service and road traffic characteristics. The problem of motorcycle rider's behavior that tends to be disorderly highly affects the road service level. One of the solutions that ca be implemented is to provide exclusive motorcycle lanes. This study begins with data collection in accordance with the parameters required as a basis to determine the needs of motorcycle exclusive lane and the road performance analysis with the parameters namely capacity, degree of saturation, level of service, and speed. The main criterion for the needs of motorcycle lanes is the proportion of large type motorcycles of $34,5 \%$ in passenger car units/hour. Based on the analysis results motorcycle volume has a large influence on the degree of saturation and level of service. Overall, the motorcycle lane application is very effective to increase road performance because the level of service rises from $F$ to $C$. While non-motorbike lanes experienced a slight decline in level of service from $B$ to $C$. Road saturation projected by looking at the vehicles-volume growth in the next 5 years, the irrelevant results between very high saturation in the motor exclusive lane of 1,44 obtained by normal vissim simulation lane speed of $38 \mathrm{~km} /$ hour. A solution is made by changing the motor EMP value from 0,25 to 0,13 . The analysis result show a significant reduction in motorcycle saturation that is equal to 0,75 so that the saturation results are relevant to the speed of the exclusive lane simulation results.
\end{abstract}

Keywords: road performance analysis, motorcycle exclusive lane, motorcycle, level of service. 


\section{PENDAHULUAN}

Sepeda motor telah menjadi moda transportasi alternatif bagi masyarakat di negaranegara berkembang, termasuk di Indonesia. Jumlah sepeda motor yang ada tentu akan mempengaruhi tingkat pelayanan jalan serta karakteristik lalu lintas ruas jalan. Ditambah masalah perilaku pengedara sepeda motor yang cenderung tidak tertib serta pertumbuhan angka pengguna sepeda motor yang terus bertambah setiap tahun membuat tingkat pelayanan jalan sangat terpengaruhi oleh adanya para pengguna sepeda motor. Menindaklanjuti dampak yang ditimbulkan oleh jumlah sepeda motor maka analisis tentang pegaruh volume sepeda motor terhadap tingkat pelayanan suatu ruas jalan menjadi penting untuk dibahas dan diberikan solusinya agar dapat mengurangi dampak yang ditimbulkan, khususnya pada ruas-ruas jalan arteri yang merupakan penghubung pusat primer ke pusat primer lainnya. Salah satu ruas jalan arteri yang membutuhkan perhatian terhadap sepeda motor yaitu pada ruas Jalan Margonda Raya.

Lajur khusus sepeda motor dengan konsep kehomogenan dari pergerakan lalu lintas pada lajur jalan yang dipisah adalah suatu alternatif untuk mengurangi konflik lalu lintas [1]. Lajur sepeda motor dibagi menjadi dua jenis, yaitu lajur inklusif dan ekslusif. Lajur inklusif adalah lajur yang memisahkan sepeda motor dengan kendaraan lain menggunakan rambu rambu lalu lintas dan rambu jalan. Sedangkan lajur ekslusif menggunakan separator maupun kerb [2]. Tujuan dari desain lajur sepeda motor ekslusif adalah untuk mengisolasi sepeda motor dari lalu lintas yang bercampur [3]. Selanjutnya untuk metode penelitian yang sangat terbatas maka pengembangannya menggunakan konsep sepeda karena keduanya dinilai mempunyai banyak kesamaan [4]. Adapun tujuan yang ingin dicapai pada penelitian ini yaitu sebagai berikut:

1. Menentukan dampak adanya volume sepeda motor terhadap kinerja ruas jalan arteri yang diamati.

2. Menganalisis dampak terhadap kinerja jalan dengan diberlakukannya lajur khusus sepeda motor pada ruas jalan arteri.

3. Menentukan prediksi kejenuhan lajur sepeda motor 5 tahun yang akan datang disertai solusi terhadap derajat kejenuhan lajur kusus prediksi 5 tahun kedepan yang paling relevan.

Konsep perencanaan lajur khusus sepeda motor dapat dilakukan dengan melihat indikator yang berpengaruh dalam penetapan kebutuhan lajur sepeda motor yaitu terrlihat pada tabel 1 .

Tabel. 1 Indikator penetapan kebutuhan lajur sepeda motor pada ruas jalan

\begin{tabular}{llcccc}
\hline \multirow{2}{*}{ No } & & & \multicolumn{3}{c}{ Nilai Indikator } \\
\cline { 4 - 6 } & & Satuan & $\begin{array}{c}\text { Batas } \\
\text { Bawah }\end{array}$ & Rata-rata & $\begin{array}{c}\text { Batas } \\
\text { Atas }\end{array}$ \\
\hline 1 & Kecepatan Operasional SM & & 33,06 & 38,62 & 44,17 \\
2 & Kecepatan Operasional KR & $\mathrm{km} / \mathrm{jam}$ & 42,17 & 49,53 & 56,90 \\
3 & Kecepatan Operasional KB & $\mathrm{km} / \mathrm{jam}$ & 35,82 & 41,83 & 47,87 \\
4 & Proporsi SM pada VJP & $\%$ & 58,07 & 66,20 & 74,92 \\
\hline 5 & Proporsi SM pada VJP (SMP) & $\%$ & 25,71 & 34,30 & 42,89 \\
6 & Vol. SM pada VJP & SM/jam & 2,696 & 4,734 & 6,771 \\
7 & Vol. SM pada VJP (SMP) & SMP/jam & 674 & 1,184 & 1,693
\end{tabular}




\begin{tabular}{cccccc}
\hline \multirow{2}{*}{ No } & Parameter & Satuan & \multicolumn{3}{c}{ Nilai Indikator } \\
\cline { 3 - 6 } & & $\begin{array}{c}\text { Batas } \\
\text { Bawah }\end{array}$ & Rata-rata & $\begin{array}{c}\text { Batas } \\
\text { Atas }\end{array}$ \\
\hline 8 & Derajat Kejenuhan & Q/C & 0,44 & 0,65 & 0,86 \\
9 & Proporsi Kecelakaan SM & $\%$ & 40 & 30 & 81 \\
\hline
\end{tabular}

Ket ; SM : Sepeda Motor ; KR : Kendaraan Ringan ; KB : Kendaraan Berat

Sumber: Idris, 2007

Untuk perencanaan lebar lajur khusus sepeda motor berdasarkan penelitian sebelumnya yag pernah dilakukan dengan menentukkan nilai batas atas dan batas bawah untuk jarak dua sepeda motor secara paralel seperti yang terlihat pada gambar 1.

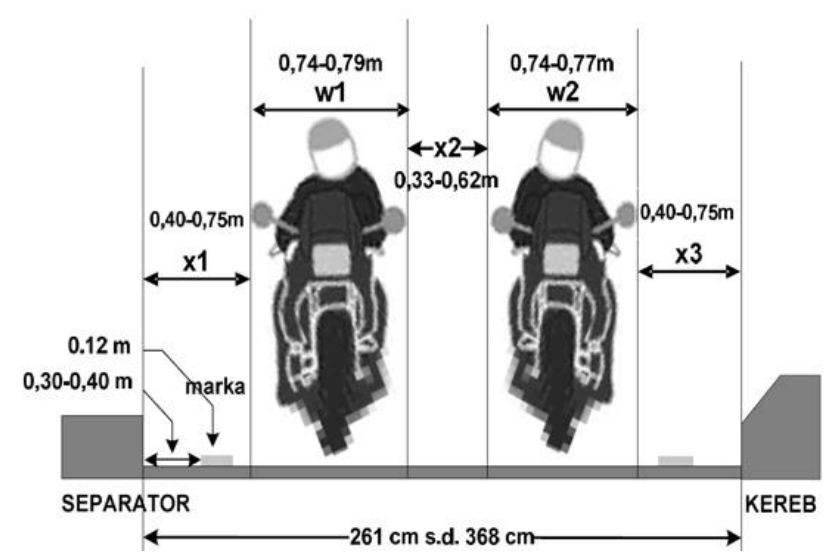

Gambar. 1 Kebutuhan Lebar Lajur untuk Dua Pergerakan Sepeda Motor Secara Paralel Sumber: Idris, 2007

Selajutnya pada penelitian ini akan dihitung kinerja ruas jalan kondisi eksisting di lapangan berdasarkan MKJI 1997 serta kinerja ruas jalan apabila diterapkan lajur khusus sepeda motor. Beberapa indikator dalam menghitung kinerja ruas jalan yaitu derajat kejenuhan (DS), kecepatan kendaraan, dan tingkat pelayanan jalan (LoS). Untuk perhitungan kinerja ruas jalan apabila diterapkan lajur khusus sepeda motor, perhitungan kecepatan kendaraan dilakukan dengan bantuan simulasi menggunakan aplikasi Vissim. Sebelumnya keadaan eksisting juga disimulasikan untuk melihat simulasi benar dan dapat diterima berdasarkan visualisasi serta perbandingan rata-rata kecepatan kendaraan kondisi eksisting dan simulasi. Pada simulasi Vissim dapat dimodelkan jenis konfigurasi geometrik dan perilaku pengguna jalan yang terjadi [5]. Hasilnya dapat dibandingkan bagaimana kinerja ruas jalan setelah diterapkan lajur khusus sepeda motor dan dilanjutkan dengan melihat juga pengaruhnya pada 5 tahun yang akan datang. Proyeksi pertumbuhan lalu lintas 5 tahun yang akan datang dihitung dengan menggunakan analisis statistik regresi linear berdasarkan data sekunder volume kendaraan pada tahun sebelumnya dan volume kendaraan tahun sekarang. Analisis kinerja ruas jalan 5 tahun yang akan datang juga dilihat dari DS, kecepatan kendaraan berdasarkan simulasi, tingkat pelayanan jalan, dan disertai dengan rekomendasi solusi sesuai dengan keadaan dan literatur yang ada.

\section{METODE PENELITIAN}

Sumber data yang dibutuhkan pada penelitian ini yaitu dari data primer dan data sekunder. Data primer didapatkan dengan melakukan survei langsung pada lokasi survei 
yaitu pada Jalan Margonda Raya 2 dengan lokasi pegambilan data sepanjang 200 meter dari setelah hotel Bumi Wiyata sampai dengan Total Buah Segar. Survei kendaraan dilakukan pada hari libur yang diwakili hari Minggu dan hari kerja yang diwakili pada hari Senin yang menghasilkan data volume arus lalu lintas, kecepatan tiap jenis kendaraan, geometrik jalan, dan hambatan samping yang terjadi di sekitar lokasi penngambilan data. Perhitungan volume arus lalu lintas dan kecepatan kendaraan dibagi menjadi 10 jenis kendaraan yaitu motor matic, mator non matic, motor sport, mobil sedan, utilitas, truk kecil, truk sedang, truk besar, bus sedang, dan bus besar.

Data sekunder yaitu volume kendaraan pada tahun sebelumnya didapat dari instansi terkait yaitu dalam penelitian ini Dishub Kota Depok. Bagan alir megenai metode penelitian yang digunakan pada penelitian ini dapat dilihat pada gambar 2.

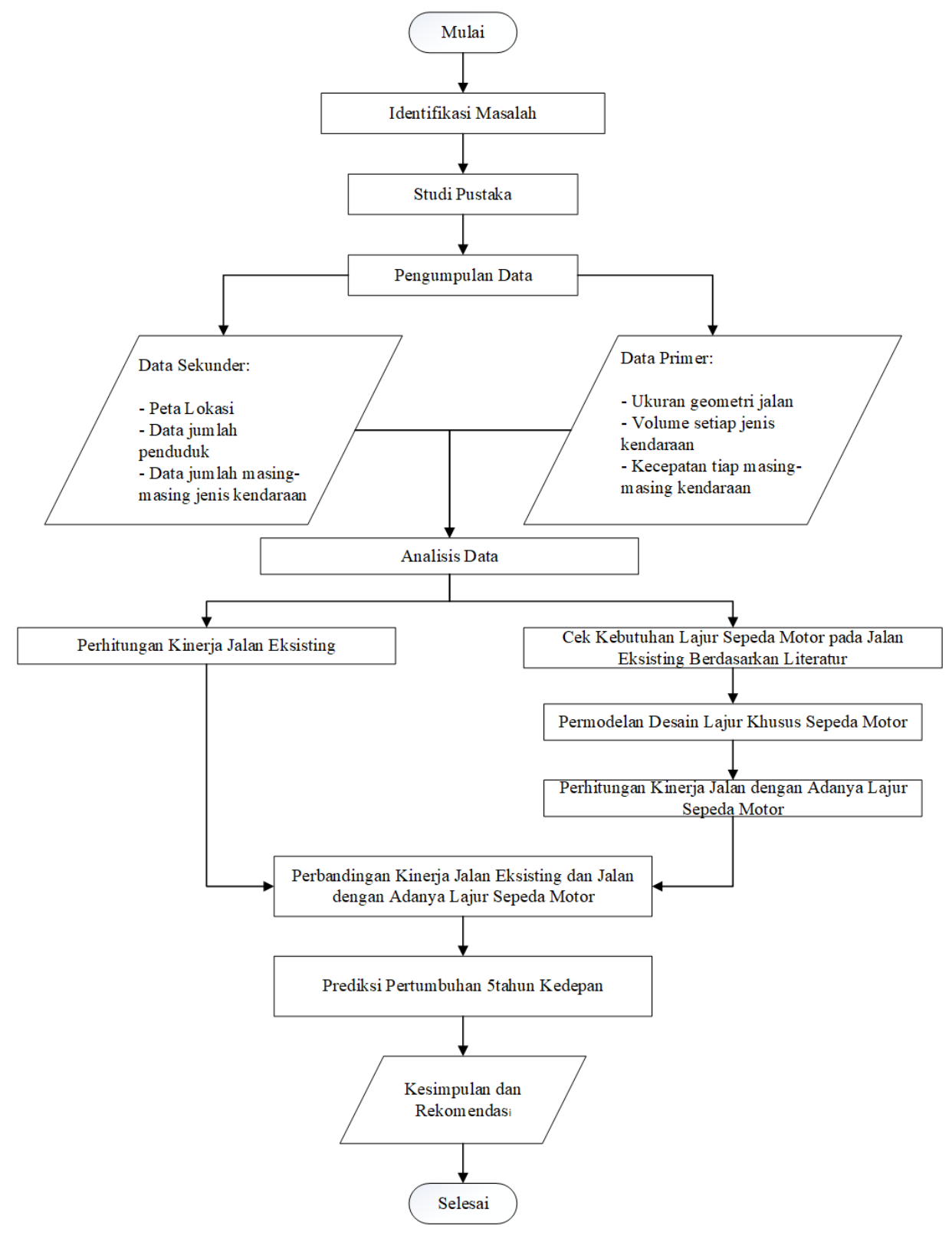

Gambar. 2 Bagan Alir Penelitian 


\section{HASIL DAN PEMBAHASAN}

Berdasarkan hasil survei yang dilakukan pada jalan Margonda Raya 2, diketahui jam puncak untuk hari libur terjadi pada pukul 11.45 - 12.45 dan pada hari kerja pada pukul 07.00 - 08.00. Setelah volume arus lalu lintas, kecepatan kendaraan, dan hambatan samping pada jam puncak diolah maka dapat di analisis sebagai berikut:

\section{Analisis Kinerja Jalan Kondisi Eksisting}

Analisis kinerja jalan eksisting dihitung berdasarkan MKJI 1997 dan didapatkan volume lalu lintas (Q) pada jam sibuk hari libur untuk arah Depok $2629 \mathrm{smp} / \mathrm{jam}$ dan arah Jakarta 2890,6 smp/jam, sedangkan volume jam sibuk pada hari kerja arah Depok sebesar 2078,35smp/jam dan arah Jakarta 3464,5 smp/jam. Hambatan samping yang terjadi pada lokasi yaitu dengan tingkat hambatan samping sedang dengan kecepatan arus bebas (FV) yaitu $62,37 \mathrm{~km} / \mathrm{jam}$.

Untuk menghitung kapasitas jalan menggunakan rumus dibawah ini:

$C=\operatorname{Co} \times F C w \times F C s p \times$ FCSF $x$ FCCS

Dimana:

$\mathrm{C}=$ Kapasitas $(\mathrm{smp} / \mathrm{jam})$

$\mathrm{C}_{\mathrm{o}} \quad=$ kapasitas dasar $(\mathrm{smp} / \mathrm{jam})$

$\mathrm{FC}_{\mathrm{w}} \quad=$ faktor penyesuai lebar jalan

$\mathrm{FC}_{\mathrm{SP}} \quad=$ faktor penyesuai kapasitas berdasarkan arah (untuk jalan terpisah)

$\mathrm{FC}_{\mathrm{SF}} \quad=$ faktor gaya gesek samping dan bahu jalan dan kerb

$\mathrm{FC}_{\mathrm{CS}} \quad=$ faktor penyesuai berdasarkan ukuran kota

Berdasarkan rumus diatas didapatkan nilai kapasitas (C) ruas jalan Margonda Raya 2 yaitu 5065,632 smp/jam. Selanjutnya dapat dihitung derajat kejenuhan (DS) pada ruas jalan Margonda Raya 2 dimana derajat kejenuhan yaitu rasio perbandingan antara arus (Q) dan kapasitas (C) [6]. Derajat kejenuhan dihitung dengan rumus dibawah ini:

$D S=\frac{Q}{C}$

Dimana:

DS = Derajat kejenuhan

Q $\quad=$ Volume arus lalu lintas ( $\mathrm{smp} / \mathrm{jam})$

C $\quad=$ Kapasitas $(\mathrm{smp} / \mathrm{jam})$

Dengan rumus diatas, didapatkan nilai DS dan tingkat pelayanan jalan jalan (LoS) pada ruas jalan Margonda Raya 2 pada tabel 2.

Tabel. 2 Tingkat Pelayanan Jalan Margonda Raya 2

\begin{tabular}{cccccc}
\hline Hari & Arah & $\begin{array}{c}\text { Volume (smp/ } \\
\text { jam) }\end{array}$ & $\begin{array}{c}\text { Kecepatan Kendaraan } \\
\text { Ringan Existing } \\
(\mathrm{km} / \text { jam })\end{array}$ & DS & LOS \\
\hline \multirow{2}{*}{ Minggu } & Jakarta & 2890,6 & 47,30 & 0,57 & B \\
& Depok & 2629 & 4,47 & 0,52 & F \\
& Jakarta & 3464,5 & 41,96 & 0,68 & B \\
& Depok & 2078,35 & 43,26 & 0,41 & B \\
\hline
\end{tabular}


Dari hasil analisis tingkat pelayanan jalan didapatkan mayoritas pelayanan jalan Margonda Raya 2 berada pada tingkat pelayanan B dengan derajat kejenuhan rata-rata di bawah 0,7 tetapi pada kondisi minggu sibuk arah Depok memiliki tingkat pelayanan F walaupun derajat kejenuhan tetap kecil dari 0,7. Hal ini terjadi karena pada Minggu sibuk arah Depok kendaraan mengalami kepadatan lalu lintas yang sangat tinggi yaitu sebesar $587,8 \mathrm{smp} / \mathrm{km}$ yang menyebabkan kemacetan dalam durasi yang cukup lama dimana kepadatan merupakan perbandingan antara volume dengan kecepatan kendaraan, maka sesuai dengan pernyataan pada Peraturan Menteri Perhubungan Nomor 96 Tahun 2015 kepadatan lalu lintas yang sangat tinggi, arus tertahan, terjadi antrian kendaraan yang panjang, kecepatan dan volume turun sampai nol, serta kecepatan rata-rata kurang dari $30 \mathrm{~km} / \mathrm{jam}$ membuat pada kondisi ini tingkat pelayanan adalah F. Sedangkan pernyataan pada Peraturan Menteri Perhubungan Nomor 14 Tahun 2006 arus tertahan, macet, dan kecepatan rata-rata kecil dari 15 km/jam juga termasuk dalam tingkat pelayanan $\mathrm{F}$.

\section{Analisis Pengaruh Volume Sepeda Motor terhadap Kinerja Jalan}

Analisis pengaruh volume sepeda motor dilakukan untuk melihat sejauh mana pengaruh keberadaan sepeda motor di jalan terhdap derajat kejenuhannya. Perhitungan yaitu dengan menghilangkan volume sepeda motor pada Jalan Margonda Raya 2 dan dilihat derajat kejenuhannya dengan kapasitas jalan yang sama. Hasilnya perubahan terbesar terjadi pada hari kerja arah Jakarta dari DS 0,68 menjadi 0,34 yang berarti keadaan pada Senin sibuk volume motor lebih dari setengah dari volume total seluruh kendaraan pada saat tersebut. Hal tersebut menunjukkan volume motor sangat berpengaruh terhadap derajat kejenuhan jalan.

\section{Perencanaan Lajur Khusus Sepeda Motor}

Perencanaan lajur khusus sepeda motor sesuai dengan batasan lebar lajur pada literatur dan menyesuaikan dengan kondisi pada ruas jalan Margonda Raya 2 maka ditentukan lebar lajur khusus sepeda motor untuk arah Jakarta 3,5 meter dan arah Depok 3 meter. Dapat dilihat pada gambar 3.

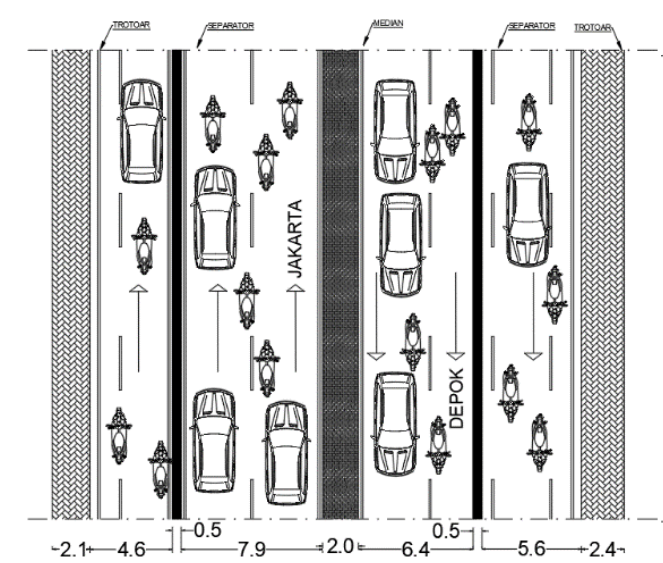

(a)

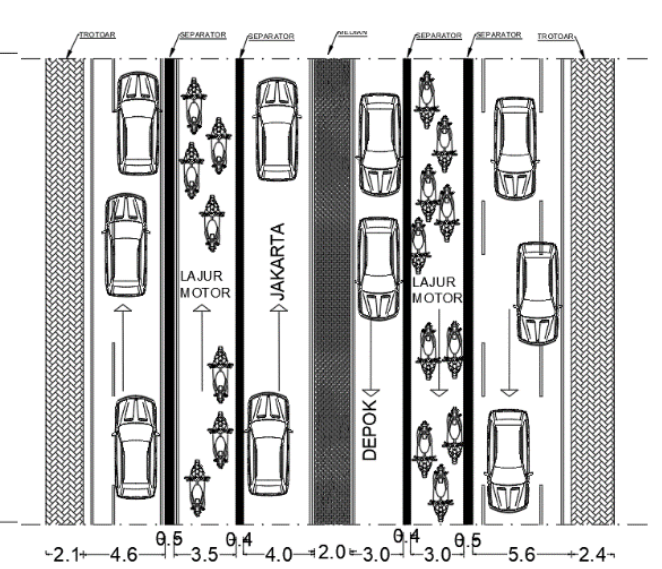

(b)

Gambar. 3 (a) Sebelum adanya lajur khusus (b) Setelah adanya lajur khusus

\section{Simulasi Menggunakan Software Vissim}

Simulasi menggunakan vissim digunakan untuk melihat bagaimana pengaruh apabila diterapkannya lajur khusus sepeda motor pada ruas jalan Margonda Raya 2 salah 
satunya dilihat dari segi kecepatan kendaraan. Hasil simulasi dapat dilihat pada gambar 4 dan gambar 5.

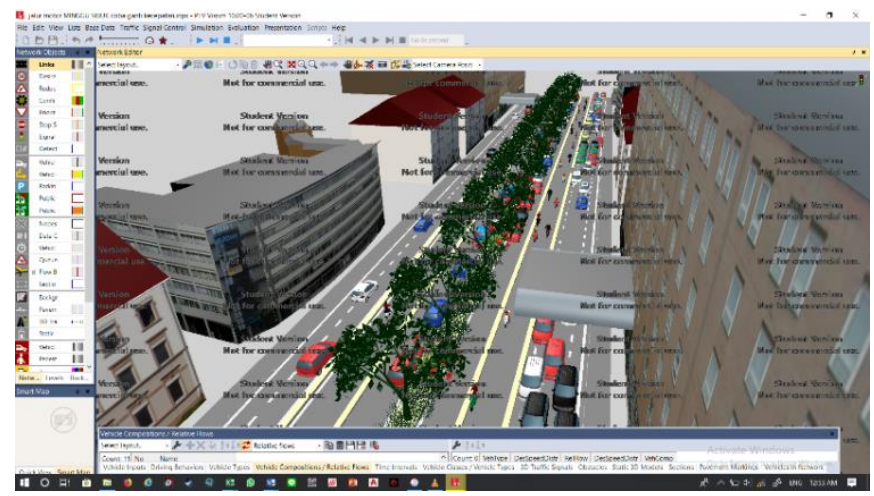

Gambar. 4 Hasil Simulasi Penerapan Jalur Motor Jam Sibuk Hari Libur

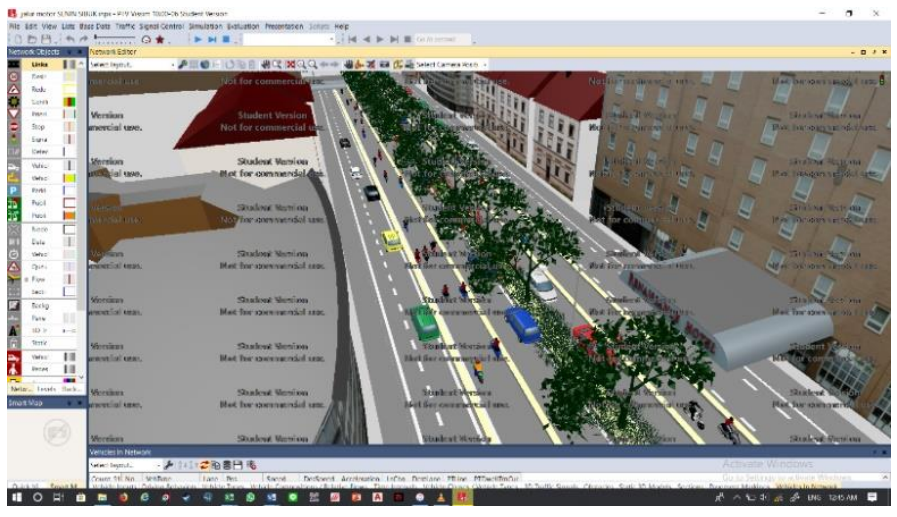

Gambar. 5 Hasil Simulasi Penerapan Jalur Motor Jam Sibuk Hari Kerja

Setelah lajur khusus sepeda motor diterapkan pada simulasi maka dapat dilihat bagaimana perubahan kecepatan kendaraan setelah adanya lajur khusus sepeda motor. Hasil kecepatan kendaraan setelah adanya lajur khusus sepeda motor dapat dinyatakan pada tabel 3. Pada tabel dapat dilihat bahwa terdapat beberapa kendaraan yang mengalami penurunan dan kenaikan terhadap kecepatannya. Hal ini dapat terjadi karena ada perubahan lebar lajur pada ruas jalan karena diterapkannya lajur khusus sepeda motor.

Tabel. 3 Kecepatan Rata-Rata Kendaraan Hasil Simulasi Setelah Ada Lajur Khusus Motor

\begin{tabular}{ccccc}
\hline \multirow{2}{*}{$\begin{array}{c}\text { Jenis } \\
\text { Kendaraan }\end{array}$} & \multicolumn{2}{c}{ Kecepatan Rata-Rata Setelah Ada Lajur Khusus Sepeda Motor } \\
\cline { 2 - 5 } & \multicolumn{2}{c}{ Minggu sibuk } & \multicolumn{2}{c}{ Senin sibuk } \\
\cline { 2 - 5 } & \multicolumn{2}{c}{$\begin{array}{c}\text { Arah } \\
\text { Depok }\end{array}$} & $\begin{array}{c}\text { Arah } \\
\text { Depok }\end{array}$ & Arah Jakarta \\
\cline { 2 - 5 } & \multicolumn{2}{c}{ Hasil Simulasi } & 46,95 & 55,39 \\
matic & 35,26 & 47,31 & 41,24 & 48,56 \\
non matic & 30,65 & 46,84 & 43,98 & 45,60 \\
sport & 36,36 & 50,50 & 36,22 & 42,83 \\
car(sedan) & 4,59 & 42,67 & 35,30 & 41,14 \\
utilitas & 5,08 & 43,91 & &
\end{tabular}




\begin{tabular}{ccccc}
\hline bus sedang & 3,24 & 33,94 & 28,09 & 33,94 \\
bus besar & 2,65 & 35,25 & 29,88 & 39,47 \\
truk kecil & 4,12 & 38,00 & 31,65 & 39,15 \\
truk sedang & 3,58 & 37,88 & 34,84 & 37,48 \\
truk besar & 3,62 & - & 32,49 & - \\
\hline
\end{tabular}

\section{Kinerja Jalan dengan Adanya Lajur Khusus Sepeda Motor}

Faktor yang berubah saat menghitung kinerja jalan setelah adanya lajur khusus sepeda motor adalah kapasitas jalan (C). Jalan Margonda Raya 2 yang sebelumnya dalam penentuan faktor-faktor kapasitas diperhitungkan sebagai jalan dengan 6 lajur 2 arah setelah adanya lajur khusus motor menjadi jalan satu arah untuk jalur motor dan untuk jalur mobil menjadi 4 lajur 2 arah terbagi. Perubahan kapasitas setelah adanya lajur khusus sepeda motor tentu juga akan berpengaruh terhadap derajat kejunuhan Jalan Margonda Raya 2 serta tingkat pelayanan yang diberikan. Kondisi yang akan dihitung yaitu adalah kondisi jam sibuk hari kerja dan jam sibuk hari libur. Hasil kapasitas Jalan Margonda Raya 2 yang baru, derajat kejunuhan dan tingkat pelayanan dapat dilihat pada tabel 4 dan tabel 5.

Tabel. 4 Kapasitas Jalan Margonda Raya 2

\begin{tabular}{cccc}
\hline \multirow{2}{*}{ Hari } & \multirow{2}{*}{ Arah } & \multicolumn{2}{c}{ C (smp/jam) } \\
\cline { 3 - 4 } & & Lajur mobil & Lajur khusus motor \\
\hline \multirow{2}{*}{ Minggu } & Jakarta & 3492,72 & 1633,5 \\
& Depok & 2975,28 & 1502,82 \\
\hline \multirow{2}{*}{ Senin } & Jakarta & 3492,72 & 1633,5 \\
& Depok & 2975,28 & 1502,82 \\
\hline
\end{tabular}

Tabel. 5 Derajat Kejenuhan dan Tingkat Pelayanan Jalan Margonda Raya 2

\begin{tabular}{|c|c|c|c|c|c|c|c|c|c|}
\hline \multirow[b]{2}{*}{ Hari } & \multirow[b]{2}{*}{ Arah } & \multicolumn{4}{|c|}{ Lajur Mobil } & \multicolumn{4}{|c|}{ Lajur Khusus Motor } \\
\hline & & DS & $\begin{array}{c}\text { Kecepatan } \\
(\mathrm{km} / \mathrm{jam})\end{array}$ & Kepadatan & LOS & DS & $\begin{array}{c}\text { Kecepatan } \\
(\mathrm{km} / \mathrm{jam})\end{array}$ & Kepadatan & LOS \\
\hline \multirow{2}{*}{ Minggu } & Jakarta & 0,57 & 43,29 & 45,9 & B & 0,55 & 48,22 & 18,7 & B \\
\hline & Depok & 0,65 & 4,84 & 398,9 & $\mathrm{~F}$ & 0,47 & 34.09 & 20,5 & $\mathrm{C}$ \\
\hline \multirow{2}{*}{ Senin } & Jakarta & 0,49 & 41,99 & 40,5 & B & 1,08 & 49,85 & 35,4 & $\mathrm{C}$ \\
\hline & Depok & 0,46 & 35,76 & 38,2 & $\mathrm{C}$ & 0,47 & 44,06 & 16,2 & B \\
\hline
\end{tabular}

Berdasarkan tabel 5 dapat dilihat derajat kejenuhan Jalan Margonda Raya 2 pada jalur mobil 4 lajur 2 arah nilainya masih kecil dari 0,75 baik itu pada hari libur maupun hari kerja, nilai ini masih sesuai dengan syarat pada MKJI 1997 namun untuk derajat kejenuhan jalur motor pada Senin pagi (jam sibuk) arah Jakarta memiliki nilai yang tinggi yaitu $1,08 \geq 0,75$. Hal ini terjadi karena jumlah sepeda motor pada Senin pagi volumenya sangat besar bahkan mencapai empat kali lipat jumlah mobil dapat dilihat pada jalur mobilnya nilai derajat kejenuhan menurun dari sebelum ada jalur motor dengan tipe jalan masih 6 lajur 2 arah yaitu 0,68 menjadi 0,49.

Berdasarkan tabel diatas untuk lajur mobil dapat dilihat bahwa tingkat pelayanan jalan setelah adanya lajur khusus memiliki tingkat pelayanan mayoritas B dengan derajat kejenuhan rata-rata di bawah 0,7 tetapi pada kondisi minggu sibuk arah Depok memiliki 
tingkat pelayanan $\mathrm{F}$ walaupun derajat kejenuhan tetap kecil dari 0,7 . Hal ini terjadi karena pada Minggu sibuk arah Depok kendaraan mengalami kepadatan lalu lintas yang sangat tinggi yaitu sebesar 398,9 smp/km yang menyebabkan kemacetan dalam durasi yang cukup lama, maka sesuai dengan pernyataan pada Peraturan Menteri Perhubungan Nomor 96 Tahun 2015 kepadatan lalu lintas yang sangat tinggi, arus tertahan, terjadi antrian kendaraan yang panjang, kecepatan dan volume turun sampai nol, serta kecepatan rata-rata kurang dari $30 \mathrm{~km} / \mathrm{jam}$ membuat pada kondisi ini tingkat pelayanan adalah F. Sedangkan pernyataan pada Peraturan Menteri Perhubungan Nomor 14 Tahun 2006 arus tertahan, macet, dan kecepatan rata-rata kecil dari 15 km/jam juga termasuk dalam tingkat pelayanan $\mathrm{F}$.

Selanjutnya untuk analisis tingkat pelayanan pada lajur khusus motor didapatkan tingkat pelayanan B pada hari Minggu arah Jakarta dan hari Senin arah Depok, serta tingkat pelayanan C pada hari Minggu arah Depok dan hari Senin arah Jakarta. Pada kondisi hari Senin arah Jakarta tingkat pelayanan $\mathrm{C}$ tersebut memiliki derajat kejenuhan $1,08 \geq$ 0,8 tetapi kepadatan yang terjadi masih tergolong sedang sebesar $35,4 \mathrm{smp} / \mathrm{km}$ sehingga berdasarkan Peraturan Menteri Perhubungan Nomor 96 Tahun 2015 tingkat pelayanan termasuk pada tingkat pelayanan $\mathrm{C}$.

\section{Perbandingan Kinerja Jalan Eksisting dan Jalan dengan Adanya Lajur Khusus Sepeda Motor}

Perbandingan kinerja jalan pada Jalan Margonda Raya 2 sebelum dan sesudah diterapkannya lajur khusus sepeda motor dapat dilihat pada tabel 6 .

Tabel. 6 Perbandingan Kinerja Jalan

\begin{tabular}{|c|c|c|c|c|c|c|c|c|c|c|}
\hline \multirow{3}{*}{ Hari } & \multirow{3}{*}{ Arah } & \multicolumn{3}{|c|}{ Sebelum Penerapan } & \multicolumn{6}{|c|}{ Sesudah Penerapan } \\
\hline & & \multirow[b]{2}{*}{ DS } & \multirow[b]{2}{*}{$\begin{array}{c}\text { Kecepatan } \\
(\mathrm{km} / \mathrm{jam})\end{array}$} & \multirow[b]{2}{*}{ LOS } & \multicolumn{3}{|c|}{ Lajur Mobil } & \multicolumn{3}{|c|}{ Lajur Khusus Motor } \\
\hline & & & & & DS & $\begin{array}{c}\text { Kecepatan } \\
(\mathrm{km} / \mathrm{jam})\end{array}$ & LOS & DS & $\begin{array}{c}\text { Kecepatan } \\
(\mathrm{km} / \mathrm{jam})\end{array}$ & LOS \\
\hline \multirow{2}{*}{ Minggu } & Jakarta & 0,57 & 47,30 & B & 0,57 & 43,29 & B & 0,55 & 48,22 & B \\
\hline & Depok & 0,52 & 4,47 & $\mathrm{~F}$ & 0,65 & 4,84 & $\mathrm{~F}$ & 0,47 & 34.09 & $\mathrm{C}$ \\
\hline \multirow{2}{*}{ Senin } & Jakarta & 0,68 & 41,96 & $\mathrm{~B}$ & 0,49 & 41,99 & B & 1,08 & 49,85 & $\mathrm{C}$ \\
\hline & Depok & 0,41 & 43,26 & $\mathrm{~B}$ & 0,46 & 35,76 & $\mathrm{C}$ & 0,47 & 44,06 & $\mathrm{~B}$ \\
\hline
\end{tabular}

Berdasarkan tabel 6 dapat dilihat bahwa tingkat pelayanan jalan sebelum dan setelah adanya lajur khusus sepeda motor terjadi perubahan yang disebabkan oleh pengurangan kapasitas dan perubahan kepadatan jalan serta berakibat pada perubahan kecepatan kendaraan. Tingkat pelayanan jalan hari Minggu arah Depok untuk lajur mobil sesudah adanya lajur khusus motor merupakan tingkat pelayanan $\mathrm{F}$ dan merupakan tingkat pelayanan paling buruk, keadaan ini tetap sama seperti sebelum diterapkan nya lajur khusus sepeda motor, namun untuk lajur motor tingkat pelayanan jalan menjadi $\mathrm{C}$ atau lebih baik dari sebelum adanya lajur khusus. Maka dapat disimpulkan bahwa pada kondisi kemacetan dengan jumlah motor yang tidak dominan, penerapan lajur khusus sepeda motor memperbaiki tingkat pelayanan untuk motor yang terlihat dari kenaikan kecepatan perjalanan motor. 


\section{Analisis Proyeksi Pertumbuhan 5 Tahun Kedepan}

Dari data primer yang telah didapat berdasarkan survei di lapangan dan data sekunder dari instansi yang berwenang, maka pertumbuhan lalu lintas dapat diproyeksikan terhadap kondisi 5 tahun kedepan berdasarkan nilai pertumbuhan menggunakan analisis regregi linear. Hasil perhitungan regresi linier kendaraan ringan dinyatakan pada gambar grafik 6 .

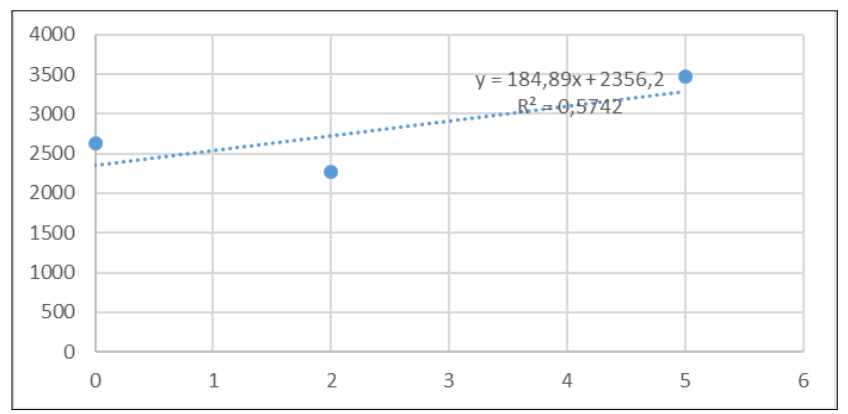

Gambar. 6 Grafik Regresi Linear

Pada grafik 6 yaitu grafik regresi linier diperoleh persamaan $\mathrm{Y}=184,89 \mathrm{x}+2356,2$ dengan nilai $\mathrm{R} 2=0,5742$ yang berarti tingkat hubungan antar variable kuat, Persentase Pertumbuhan Lalu Lintas per tahunnya yaitu sebesar 6,63\%, maka volume kendaraan dengan memperhitungkan pertumbuhan pada 5 tahun yang akan datang yaitu sebesar 4613,4 smp/jam. Selanjutnya kinerja jalan Margonda Raya 2 pada 5 tahun kedepan dapat dilihat pada tabel 7 .

Tabel. 7 Kinerja Jalan 5 Tahun Kedepan

\begin{tabular}{ccc}
\hline & Lajur mobil & Lajur khusus motor \\
\hline $\mathrm{DS}$ & 0,65 & 1,44 \\
\hline $\mathrm{V}(\mathrm{km} / \mathrm{jam})$ & 40 & 38 \\
\hline
\end{tabular}

Berdasarkan Peraturan Menteri Perhubungan No: KM 96 Tahun 2015 tingkat pelayanan Jalan Margonda Raya lima tahun kedepan, pada lajur mobil tergolong tingkat pelayanan B karena nilai derajat kejenuhan hanya sebesar 0,65 dan kecepatan kendaraan diratakan lebih dari $40 \mathrm{~km} / \mathrm{jam}$. Sedangkan untuk kondisi lajur motor dengan prediksi pertumbuhan motor lima tahun kedepan memiliki nilai derajat kejenuhan yang tinggi yaitu 1,44 namun kecepatan rata-rata motor sekitar $38 \mathrm{~km} / \mathrm{jam}$ dan pada simulasi secara visual keadaan lajur motor tidak mengalami kemacetan maka dapat digolongkan dengan tingkat pelayanan $\mathrm{C}$.

Nilai derajat kejenuhan yang tinggi pada lajur motor dengan kepadatan sedang, menjadi sesuatu yang harus dianalisis. Perhitungan nilai derajat kejenuhan lajur motor tinggi karena nilai EMP motor $(0,25)$ kurang sesuai dengan kondisi di lapangan. Berdasarkan penelitian sebelumnya nilai EMP sepeda motor sangat terpengaruh oleh proporsi sepeda motor pada ruas jalan [7] dan berdasarkan hasil analisis didapat nilai EMP sepeda motor menjadi 0,13 lebih kecil dari ketentuan pada MKJI 1997 yaitu sebesar 0,25. Apabila nilai 0,13 digunakan sebagai nilai EMP motor maka derajat kejenuhan lajur khusus sepeda motor pada kondisi 5 tahun kedepan menurun dari 1,44 mejadi 0,75 dan derajat 
kejenuhan pada tahun sekarang untuk lajur khusus sepeda motor dari 1,08 menjadi 0,56. Hal ini menunjukan bahwa dengan penurunan nilai EMP dapat memperbaiki nilai derajat kejenuhan. Perubahan ini dirasa bisa dilakukan karena keadaan kondisi sekarang dengan proporsi sepeda motor dan perilaku pengemudi motor yang ada mungkin sudah berubah dari pada tahun disaat pedoman Manual Kapasitas Jalan Indonesia (MKJI 1997), selain itu pernyataan ini diperkuat oleh penelitian sebelumnya yang telah dilakukan.

\section{KESIMPULAN}

Dari hasil pengolahan data survei lalu lintas pada ruas jalan arteri Margonda Raya 2 didapatkan data pengaruh volume sepeda motor terhadap tinggat pelayanan pada keadaan Senin sibuk dengan DS 0,68 adalah B jika pengguna sepeda motor dihilangkan DS ruas jalan menjadi 0,34 dengan tingkat pelayanan A. Hal ini menunjukkan bahwa para pengguna sepeda motor memiliki volume yang besar sehingga sangat berdampak terhadap tingkat pelayanan ruas jalan arteri Margonda Raya 2.

Kinerja ruas jalan Margonda Raya 2 setelah diberlakukannya lajur khusus sepeda motor untuk lajur non sepeda motor terjadi kenaikan dan penurunan derajat kejenuhan. Kinerja jalan untuk lajur sepeda motor yang mengalami perubahan besar yaitu pada keadaan Minggu siang arah depok dari tingkat pelayanan $\mathrm{F}$ menjadi $\mathrm{C}$. Hal ini menunjukkan secara keseluruhan dampak penerapan lajur khusus sepeda motor sangat efektif untuk menaikkan kinerja jalan pada lajur khusus yang hanya dilalui sepeda motor.

Hasil analisa kejenuhan jalan arteri Margonda Raya dengan lajur khusus sepeda motor melihat pertumbuhan lalu lintas 5 tahun kedepan pada lajur khusus sepeda motor didapatkan derajat kejenuhan yang sangat tinggi $>1$ yang artinya kondisi jalan macet dengan kecepatan rendah tetapi hasil simulasi vissim menunjukkan kecepatan rata-rata yang masih normal yaitu $38 \mathrm{~km} / \mathrm{jam}$. Hal ini menujukkan bahwa pada keadaan tersebut perhitungan volume kendaraan terhadap kapasitas ruas jalan lajur khusus motor sudah tidak sesuai dengan teori serta keadaan sebenarnya. Maka dari itu direkomendasikan solusi berupa relevansi koefisien ekivalensi mobil penumpang untuk kendaraan sepeda motor menjadi 0,13 dari sebelumnya 0,25.

Untuk penelitian selanjutnya sebaiknya dalam perencanaan lajur khusus juga merencanakan perubahan manajemen lalu lintas yang terjadi pasca penerapan agar dapat dilihat langsung model pengaplikasian di lapangan apabila direncanakan lajur khusus sepeda motor.

\section{DAFTAR PUSTAKA}

[1] Idris, Muhammad. 2010. Kriteria Lajur Sepeda Motor untuk Ruas Jalan Arteri Sekunder. Bandung: Puslitbang Jalan dan Jembatan

[2] Mulyadi, A.M. 2017. Influence of Motorcycles Lane to The Traffic Volume and Travel Speed in Denpasar, Indonesia. IOP Conf. Series: Earth and Environmental Science 106 2017.

[3] Quyen Le, To. 2016. A Study of Motorcycle Lane Design in Some Asian Countries. Procedia Engineering 142 (2016) 291 - 297. 
[4] Husein H, Radin Umar RS, Farhan FMS, Dadang MM. 2005. Key Component of a Motorcysle-Traffic System, A Study a long The Motorcycle Path in Malaysia, Paper on Journal IATSS Research Vol 29 No.1 2005.

[5] Aryandi, Rama Dwi. 2014. Penggunaan Software Vissim untuk Analisis Simpang Bersinyal (Studi Kasus Simpang Mirota Kampus Terban Yogyakarta), The $17^{\text {th }}$ FSTPT International Symposium Jember University 22-24 August 2014.

[6] Direktorat Jenderal Bina Marga. 1997. Manual Kapasitas Jalan Indonesia (MKJI). Jakarta: Departemen Pekerjaan Umum.

[7] Sutrisno, Agus N. 2017. Analisis Aliran Lalu Lintas Pada Ruas Jalan Perkotaan Satu Arah (Studi Kasus Jalan Margo Utomo Kota Yogyakarta). Tesis. Pascasarjana Universitas Gadjah Mada Yogyakarta. 
Intan dan Eva, Analisis Penerapan Lajur Khusus Sepeda Motor ... 